\title{
Larval crowding leads to unusual reaction norms for size and time at maturity in a geometrid moth (Lepidoptera: Geometridae)
}

\author{
HeLEN VELLAU and TOOMAS TAMMARU
}

\begin{abstract}
Department of Zoology, Institute of Ecology and Earth Sciences, University of Tartu, Vanemuise 46, EE-51014 Tartu, Estonia; e-mails: helen.vellau@ut.ee; toomas.tammaru@ut.ee
\end{abstract}

Key words. Lepidoptera, Geometridae, reaction norm, larval crowding, size and time at maturity, Ematurga atomaria

\begin{abstract}
The theory of life history evolution generally predicts a negative across-environment correlation between development time and size at maturity in response to variations in environmental quality. Deviations from this pattern occur under specific circumstances. In particular, organisms may mature both early and at a small size when (1) some ultimate change (e.g. time constraint, resource exhaustion) in the environment precludes further growth, or (2) when there are predictable among-environment differences in mortality rates. The first scenario is frequently documented in insects but evidence for the second possibility is scarce. Here we report a crowding-induced plastic response resulting in a clear positive across-environment correlation between final weight and development time in a geometrid moth. The response was apparent during the entire larval period and in the last larval instar. Crowding also led to increased growth rates. As outbreaks have not been reported for this species it is unlikely that early pupation is a response to anticipated food shortage. Instead, we suggest that crowded larvae may perceive a higher risk of predation, perhaps because they are unable to distinguish conspecifics from potential predators. A possibility for a plastic increase in growth rate implies that the uncrowded larvae grow at submaximal rates, which indicates a cost of high growth rate.
\end{abstract}

\section{INTRODUCTION}

A negative across-environment correlation between final size and development time is predicted by classical models of life history evolution (Stearns \& Koella; 1986, Roff, 1992; Stearns, 1992). In other words, within a species, juvenile organisms which grow slowly due to poor environmental conditions typically have longer development times, but such compensation is almost never complete as their final sizes are smaller than of those that develop in more favourable environments. This situation is represented by the negative slope of the bivariate reaction norm between size and time at maturity (Stearns \& Koella, 1986; Marty et al., 2011).

Optimality modelling has shown that convex reaction norms are adaptive under a broad array of assumptions (Stearns \& Koella, 1986; Kozlowski, 1992; Roff, 1992; Berrigan \& Koella, 1994; Abrams et al., 1996; Gebhardt $\&$ Stearns, 2002). In the case of insects, a negative correlation between development time and final size is indeed a typical response to varying food quality and quantity both for the entire larval period (Bauerfeind \& Fischer, 2005; Berner \& Blanckenhorn, 2007) and for each larval instar (Tammaru, 1998; Esperk \& Tammaru, 2010).

Nevertheless, positive correlations between size and time maturity are predicted (Stearns, 1992; Abrams et al., 1996; Abrams \& Rowe, 1996; Marty et al., 2011) and indeed observed in particular circumstances. Maturing quickly at a small final size appears to be adaptive in two somewhat different scenarios. First, nothing is to be gained by prolonging the juvenile period if the environment no longer supports growth, i.e., there is a shortage of food or a time constraint. Second, a positive across- environment correlation between size and time at maturity can be selected for if the environments mainly differ in mortality rates. Indeed, various models support the intuitive prediction that higher mortality rates select for earlier maturation at the expense of a smaller body size. However, the outcome can be different in more complex cases when mortality is size-selective (Gårdmark \& Dieckmann, 2006), time-dependent (Rudolf \& Rödel, 2007) or correlated with environment-specific growth rates (Marty et al., 2011), or when the (plastic) growth rate as such affects the risk of being killed by predators (Abrams \& Rowe, 1996).

The first scenario (i.e. constrained development time or resource limitation) resulting in a reaction norm with a positive slope is not uncommon in insects. Devastating environmental changes typically include exhaustion of discrete food resources (e.g. seeds, dung, plant stalks; Bonal \& Munoz, 2008; Fox et al., 1996) or onset of an unfavourable season (Tauber et al., 1986; Johansson \& Rowe, 1999; Johansson et al., 2001). However, it is less clear how frequently reaction norms with a positive slope arise due to environment-specific differences in mortality rates (the second scenario). This scenario may seem unlikely in the case of most insects, especially because this implies that an individual should be able to somehow assess the risk of being killed by predators, an ability which appears implausible for terrestrial insects that have poor powers of signal perception. An intriguing potential example is the frequently observed among-generation difference in body size that can plausibly be explained by seasonal differences in larval mortality rates (Remmel et al., 2009; Teder et al., 2010). 
The interpretation of the frequently observed plastic responses of larvae to crowding is not straightforward in the present context. Indeed, crowding larvae can result in reduced body sizes even when food is not limiting (Wall \& Begon, 1987; Barnard \& Geden, 1993; Foster \& Stiven, 1996; Agnew et al., 2002). The situation with regard to development time is more complicated as any potential adaptive response to crowding per se is typically confounded by the effects of crowding-related deterioration in overall environmental quality. Nevertheless, shorter rather than longer development times are sometimes recorded for crowded larvae (e.g. Haukioja et al., 1988; Ishii, 1994; Bauerfeind \& Fischer, 2005) and a study that was explicitly designed to separate the effects attributable to crowding from that of environmental quality found evidence for both (Tammaru et al., 2000). However, it is not immediately obvious if shorter development times in response to crowding are a means of escaping an environmental collapse (first scenario) or an adaptive response to increased mortality rates, which are frequently observed during insect outbreaks.

The aim of the present work is to report a clear case of a crowding-related plastic response in larval growth schedules, which results in a strong positive acrossenvironment correlation between final size (weight) and development time in the larvae of the geometrid moth Ematurga atomaria. In particular, the larvae of this geometrid moth pupated both earlier and at lower weights when reared in groups. The data also allowed us to determine whether crowded larvae grew faster, a piece of evidence necessary for interpreting the observed plastic change in maturation schedule in an adaptationist framework, as well as for exploring the possibility of plastic changes in growth rate per se. Additionally, applying crowding treatments at two different development stages enabled us to determine whether the plastic changes can be induced at different times during larval development.

\section{METHODS}

\section{Study species}

This study was performed on the larvae of the common heath moth, Ematurga atomaria L. (Lepidoptera: Geometridae), a day-flying moth with appr. $2.6 \mathrm{~cm}$ wing span. This widespread and common species is found in various habitats but is particularly abundant on moors and heaths. The polyphagous and colour-polymorphic larvae (Leraut, 2009) commonly feed on heather and bilberry, but also on other shrubs (Porter, 1997). They are solitary and invariably go through 5 instars. The species overwinters as a pupa and is univoltine in Northern Europe.

\section{Experimental design}

In June 2010, 12 females were collected from a peat bog near Tartu $\left(58^{\circ} 22^{\prime} \mathrm{N} ; 26^{\circ} 43^{\prime} \mathrm{E}\right)$, Estonia and allowed to oviposit in captivity. The newly hatched larvae were placed in $50 \mathrm{ml}$ rearing vials either individually or in groups of 6 larvae per vial (of which, on average 4.2 were still alive at pupation). The larvae which were reared individually throughout their development formed the "solitary" treatment as opposed to the "group" treatment. The third, "solitary to group" treatment was formed of larvae that were initially reared singly until the end of their 4th instar and then in pairs during the 5th instar. Last instar larvae are sufficiently large for two of them to inevitably interact when kept in a rearing vial. The pairs were randomly formed of sibling larvae, which had moulted to the 5th instar on the same day.

All larvae were fed leaves of bilberry (Vaccinum myrtillus). This food was provided ad libitum in all treatments with fresh branches of the host plant provided at least every third day. Rearing vials were randomised on a tray with respect to brood and treatment. This experiment was carried out at $22^{\circ} \mathrm{C}$ and a 18L : 6D photoperiod, which corresponds to the natural light conditions prevailing during the larval period. In total, there were 337 vials with 616 larvae at the beginning of the last larval instar. Separately by treatments, the initial numbers and numbers of the larvae which died during the experiment were, respectively: 120 and 20 in the "solitary" treatment, 168 and 7 in the "solitary to group" treatment and 427 and 74 in the "group" treatment. Most of the mortality occurred in the early instars.

\section{Traits recorded and data analyses}

For all larvae, development time from the day of hatching to the end of the 4th instar, as well as the duration of the 5th instar were measured by inspecting the larvae daily. Duration of the entire larval period was the sum of these two periods. The larvae were weighed at the end of the 4th instar and all pupae were weighed and sexed.

In all the analyses, "growth rate" is expressed as [(final weight $)^{1 / 3}$ - (initial weight $\left.)^{1 / 3}\right] /$ development time. When calculating the growth rate for the four first instars, initial weight was treated as zero. For the last instar the initial weight was that recorded at the end of the 4th instar. Given the data on growth allometry of Lepidoptera larvae (Tammaru \& Esperk, 2007), the cubic root transformation is more appropriate for the linearization of growth trajectories than the more traditional relative growth rate. Linearizing growth trajectories was necessary to carry out among-treatment quantitative comparisons of growth rates. Sex and final weight of the 4th instar (when appropriate) were included in the models, as parameters of larval growth are often found to systematically depend on gender and larval size.

In most cases it was not possible to distinguish between individual larvae in the group vials. As a result, in the crowding treatments, final weights of the last instar and the pupal weights of individual larvae could not be associated, so we used vialspecific averages of these variables. Similarly, we had to use the

TABLE 1. ANOVA of the differences between "group" and "solitary" reared larvae in terms of their growth parameters up to the end of 4 th instar.

\begin{tabular}{|c|c|c|c|c|c|c|}
\hline & \multicolumn{2}{|c|}{ Development time } & \multicolumn{2}{|c|}{ Weight } & \multicolumn{2}{|c|}{ Growth rate } \\
\hline & $\mathrm{F}_{\mathrm{ddf}}$ & $\mathrm{P}$ value & $\mathrm{F}_{\mathrm{ddf}}$ & $\mathrm{P}$ value & $\mathrm{F}_{\mathrm{ddf}}$ & $\mathrm{P}$ value \\
\hline Treatment & $273.7_{157}$ & $<0.0001$ & $200.8_{58}$ & $<0.0001$ & $53.1_{158}$ & $<0.0001$ \\
\hline Sex & $43.7_{581}$ & $<0.0001$ & $50.4_{587}$ & $<0.0001$ & $12.9_{566}$ & 0.0004 \\
\hline Treatment $\times$ sex & $9.5_{581}$ & 0.0021 & $20.6_{583}$ & $<0.0001$ & $0.8_{566}$ & 0.38 \\
\hline
\end{tabular}


value of "average sex" for each vial, with sex being treated as a numerical variable ( 0 for females and 1 for males). As a result, for the purpose of the statistical tests, we had just one observation per vial. As is typical for parameters of larval growth, the analyzed variables were normally distributed so no transformation was necessary.

The overall effects of crowding during the first four instars were analyzed by comparing the data of two treatments ("solitary" and "group"), the data of the "solitary to group" treatment (differing from "solitary" only in handling during the 5th instar) were combined with those of the "solitary" treatment. Two-way analyses of variance with treatment and sex as independent factors were performed for time to moulting to the last instar, weight at that moult and growth rate during the first 4 larval instars.

The effects of crowding on the entire larval growth schedule were analyzed by comparing just two treatments ("solitary" and "group"); the results for the "solitary to group" treatment were not included in this analysis. Two-way analyses with treatment and sex as independent factors were performed for development time, pupal weight and average growth rate of the five larval instars. In all these analyses (Tables 1 and 2), each larva was considered an independent observation. However, brood and vial were included in the model as random factors, which allowed us to avoid overestimating the number of degrees of freedom (Kenward-Roger method of estimating ddf was used, Kenward \& Roger, 1997; Littell et al., 1996).

The effect of crowding on the last larval instar, taken separately, was analyzed by comparing the results for all three treatments. Days spent in the last larval instar and growth rate were analyzed as dependent on treatment, sex and initial weight of this instar. All the analyses were carried out using SAS 9.1 (SAS Institute Inc., 1990).

\section{RESULTS}

Crowding resulted in a positive association between development time and final weight: crowded larvae pupated earlier and at a smaller weight than individually reared larvae. The positive relationship was apparent in terms of the treatment means both when recorded at the end of the 4th instar and entire larval period (Fig. 1). Corresponding differences in both time and weight were statistically highly significant (Tables 1 and 2). Sexes differed quantitatively but not qualitatively in their response to crowding: in all cases, the effect of crowding was somewhat stronger in females (Fig. 1a) than males (Fig. 1b). In comparison, the overall phenotypic correlation between pupal weight and total development time was weakly and non-significantly negative $(\mathrm{b}=-0.093$ $\mathrm{mg} /$ day, $\mathrm{F}_{1,593}=0.81, \mathrm{p}=0.37$; GLM model with treatment and sex as additional factors).

In the last larval instar (Fig. 2) treatment significantly affected development period $\left(\mathrm{F}_{2,248}=64.7, \mathrm{p}<0.0001\right)$
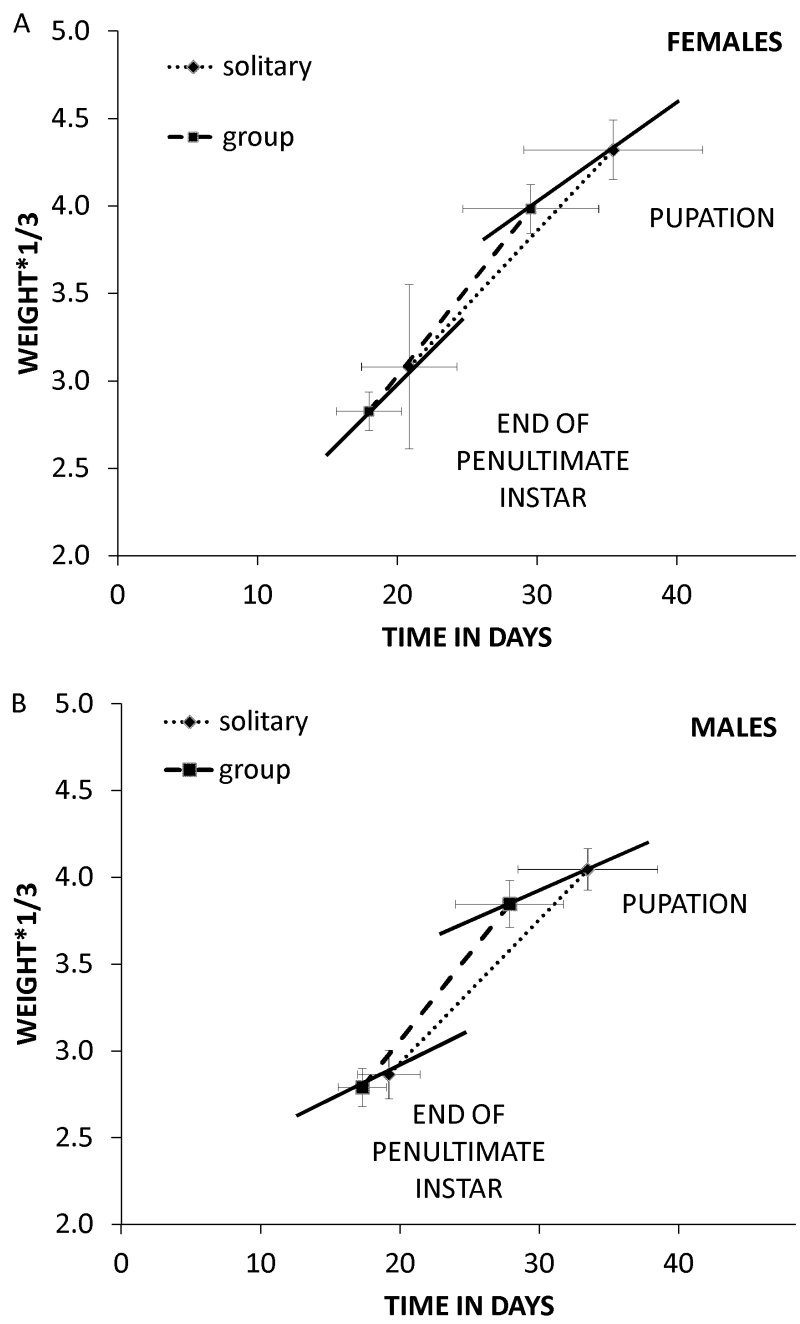

Fig. 1. The positive relationship between development time and final body weight (solid lines) of females (a) and males (b) of E. atomaria reared in the "solitary" and "group" treatments. Values were recorded at the end of the 4th (penultimate) instar and after pupation. Error bars indicate standard deviations. Weight is cubic-root transformed to linearize the growth trajectories of the larvae, which makes it easier to compare the growth rates (slopes of the dashed and dotted lines).

and growth rate $\left(\mathrm{F}_{2,248}=4.03, \mathrm{p}=0.019\right)$ within that instar. There was a consistent pattern of a positive correlation between time and weight (Fig. 2), with the "solitary to group" treatment always showing weaker crowdingrelated effects than "group". A pair wise comparison of the results for "solitary" and "solitary to group" was significant for development time (Tukey test: $\mathrm{t}=2.48$, df $=$ $252, \mathrm{p}=0.036)$ but not pupal weight $(\mathrm{t}=1.67, \mathrm{df}=257, \mathrm{p}$

TABLE 2. ANOVA of the differences between "group" and "solitary" reared larvae in terms of their parameters measured over the entire larval period.

\begin{tabular}{|c|c|c|c|c|c|c|}
\hline & \multicolumn{2}{|c|}{ Development time } & \multicolumn{2}{|c|}{ Pupal weight } & \multicolumn{2}{|c|}{ Growth rate } \\
\hline & $\mathrm{F}_{\mathrm{ddf}}$ & $\mathrm{P}$ value & $F_{\mathrm{ddf}}$ & $\mathrm{P}$ value & $F_{\text {ddf }}$ & $P$ value \\
\hline Treatment & $121.6_{120}$ & $<0.0001$ & $263.1_{163}$ & $<0.0001$ & $44.0_{167}$ & $<0.0001$ \\
\hline Sex & $27.6_{257}$ & $<0.0001$ & $201.8_{371}$ & $<0.0001$ & $0.02_{357}$ & 0.88 \\
\hline Treatment $\times$ sex & $9.9_{257}$ & 0.0019 & $33.6_{369}$ & $<0.0001$ & $1.4_{356}$ & 0.24 \\
\hline
\end{tabular}



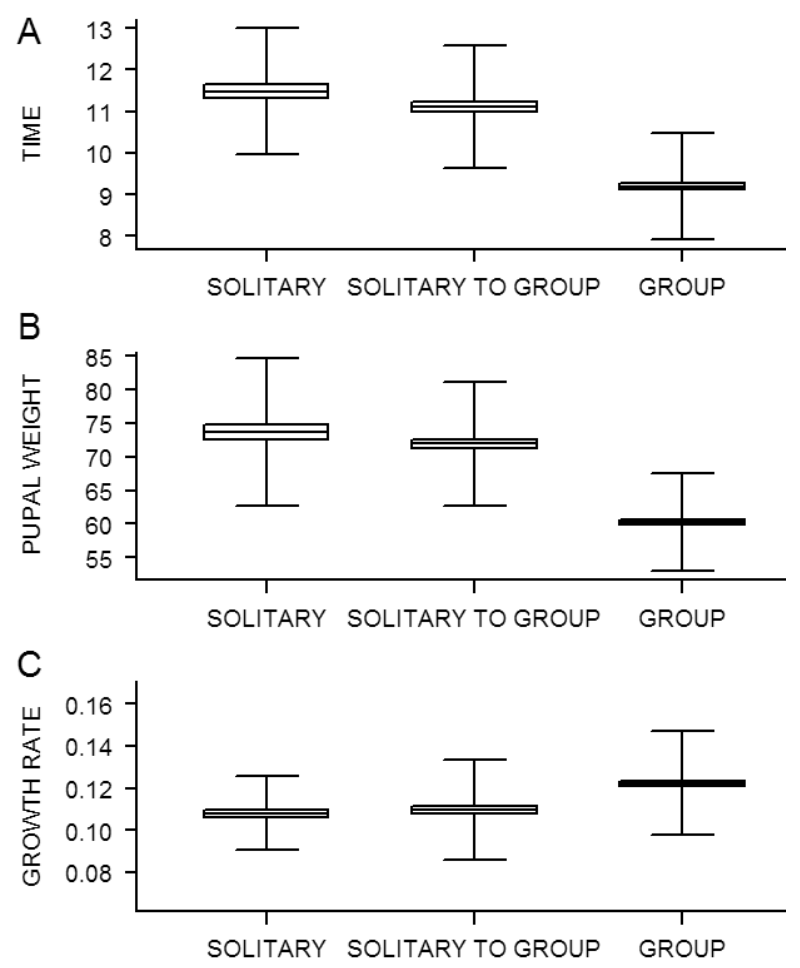

Fig. 2. Among-treatment comparisons of development times (A - measured in days), pupal weights $(\mathrm{B}-$ in $\mathrm{mg}$ ) and growth rates $\left(\mathrm{C}-\right.$ measured in $\mathrm{g}^{1 / 3} /$ day $)$ of the last instar. The values are corrected for initial weight and sex (LSMEAN statement of SAS MIXED procedure), and average values for rearing vial were used (see Methods). Error bars indicate standard deviations and boxes represent standard errors.

$=0.21)$. Nevertheless, a MANOVA for development time and pupal weight considered jointly detected a significant difference (Wilk's lambda $=0.937, \mathrm{p}=0.0036$ ) between the results for the "solitary" and "solitary to group" treatments.

Growth rates of the crowded larvae were higher both during the first four instars and in the final instar (Tables 1 and 2). During the first four instars, females grew faster than males, but there was no effect of sex on growth rate measured over the whole larval period.

\section{DISCUSSION}

The larvae of E. atomaria reared in groups pupated earlier and at smaller body weights than the larvae reared solitarily. In other words, there was a positive acrosstreatment relationship between body size and development time caused by larval crowding, i.e. a pattern which contrasts to the "standard" case - a negative correlation typically induced by variations in food quality. Our experimental design allowed us to show that the positive relationship between final size and development time is manifested both at the level of the entire larval period and the last larval instar (see Klingenberg \& Spence, 1997; Tammaru \& Esperk, 2007; Esperk \& Tammaru, 2010 for the advantages of an instar-specific approach when studying insect growth curves). Moreover, we could show that the positive slope of the reaction norm is not induced during a particular sensitive period of larval development (cf. Lester et al., 2005; Friberg et al., 2011): the response of larvae to crowding occurred both early in their development and during the final instar.

Notably, E. atomaria does not meet any of the criteria that would favour early maturation as an escape from environmental conditions that no longer support growth, i.e. the first scenario as described above. As a polyphagous external herbivore, the species is unlikely to be food-limited under normal conditions (for opposite examples, see Haukioja et al., 1988; Smits, 2002), and we are also unaware of any reports of population outbreaks for this geometrid. In this context, it is curious that the effect of crowding on larval growth was much more pronounced (though qualitatively similar) in $E$. atomaria than recorded in comparable studies on the defoliator Epirrita autumnata for which regular outbreaks are recorded (Haukioja et al., 1988; Ruohomäki et al., 2003; Sillanpää, 2008). In the latter species, crowded larvae pupate later than singly reared ones and a negative effect of larval density on development time could only be detected when the effect of environmental quality was statistically removed (Tammaru et al., 2000). Similarly, the increase in larval growth rates was more pronounced in E. atomaria. The possibility that the similarities in the response to crowding in E. atomaria and E. autumnata evolved in the remote past and are inherited from the common ancestor of these species cannot be excluded but appears unlikely as the respective lineages separated about 50 millions of years ago (Wahlberg et al., 2010).

Moreover, any interaction between crowding and the onset of an unfavourable season can hardly account for early pupation as this univoltine pupal-hibernating species has plenty of time to complete its life cycle (see Tammaru et al., 2001, for a discussion) in a region that is far from the northern limit of the species' distribution (Hulden, 2000). There is also no reason to expect a time stress driven by host plant shortage, as the larvae pupate long before autumn, and, additionally, some common host plants of the species (e.g. Calluna vulgaris) are evergreen.

With no environmental dead ends (time constraint, resource exhaustion) to escape, an adaptationist explanation for the shorter development period of crowded larvae should be sought in higher mortality rates under such conditions (the second scenario above). For this species, it is not reasonable to assume that the larvae perceiving the presence of conspecifics are selected for to escape the associated increase in mortality risk, either in the form of an infectious disease (Rothman, 1997; Greer et al., 2008), parasitism (Cote \& Poulin, 1995; Brodmann et al., 1997) or predation (Stiling, 1988). This is because such negatively density-dependent effects typically start to operate at higher densities than are usual for E. atomaria in the field. Nevertheless, we see a plausible scenario related to the elevated mortality hypothesis. In particular, the larvae may not specifically respond to the presence of conspecifics but to any other frequent interaction with other animals over short distances. Given the limited sensory abilities of lepidopteran larvae, it may not be easy for 
them to identify potential predators and the larvae may respond in a "just in case" manner by leaving an environment they perceive as unsafe. The hypothesis that such an unspecific response exists should be feasible to test but we are currently unaware of attempts to do so.

If this is the case, the response to crowding in E. atomaria accords with various observations on the plasticity of life history traits induced by the presence of predators (Crowl \& Covich, 1990; Riessen, 1999). This kind of plastic change may be a by-product of anti-predator behaviour (Ball \& Baker, 1996) or represent adaptive modifications of growth schedules per se (Beckerman et al., 2007). Within this conceptual framework, the case of E. atomaria can be considered an adaptive modification, as both growth rate and development rate are affected (see also Tammaru et al., 2000, for a related discussion of crowding effects).

In a more general context, theory predicts that growth rate may both increase and decrease in response to higher predation (Abrams \& Rowe, 1996). The rationale behind the eventual decrease in growth rates is that faster growth driven by high feeding rates may expose the actively foraging prey to potential predators and should be therefore avoided. Nevertheless, in the case of an herbivorous insect, this should primarily be the case when the predators are also invertebrates, e.g. those attracted by vibrations of the substrate (Gotthard, 2000). The effect of increased exposure due to high feeding rates is hardly dramatic if the predators are visually searching birds, which are the main predators of larger lepidopteran larvae (Remmel et al., 2011). Indeed, the feeding behaviour of E. atomaria larvae does not significantly increase their visibility (pers. obs. of the authors). If the increase in growth rate is actually an adaptive response to elevated predation risk, it may indicate that the cost of a high growth rate (see Dmitriew, 2011, for a review) lays in factors other than an increased risk of predation. The cost itself should, however, be present as the larvae increased their growth rates in response to an environmental signal, which indicates that they otherwise grow at sub-maximal rates (cf. Tammaru et al., 2004).

In summary, although we are currently unable to provide a definitive evolutionary explanation for the crowding-related plasticity in E. atomaria, this case indicates that positive correlations between size and time at maturity may well occur in species that are unlikely to experience environmental limitations such as a deterioration in their food supply or the onset of an unfavourable season. The plausible explanation rests on perceived elevated mortality rates. In addition, the increase in larval growth rates in response to crowding may deserve further attention as it could provide an opportunity to study causes and consequences of plasticity in this fundamental life history trait.

ACKNOWLEDGEMENTS. We thank D. Boukal, R. Davis, T. Esperk, J. Javoiš, A. Kaasik, T. Klemola, F. Molleman, T. Teder, A. Tiitsaar and two anonymous referees for constructive comments on earlier drafts of this manuscript. This study was supported by Estonian Science Foundation grant no. 7522, tar- geted financing project SF0180122s08 and the European Union through the European Regional Development Fund (Center of Excellence FIBIR).

\section{REFERENCES}

ABrams P.A. \& Rowe L. 1996: The effects of predation on the age and size of maturity of prey. Evolution 50: 1052-1061.

Abrams P.A., Leimar O., Nylin S. \& Wiklund C. 1996: The effect of flexible growth rates on optimal sizes and development times in a seasonal environment. Am. Nat. 147: 381-395.

Agnew P., Hide M., Sidobre C. \& Michalakis C. 2002: A minimalist approach to the effects of density-dependent competition on insect life-history traits. Ecol. Entomol. 27: 396-402.

BALl S.L. \& BAKeR R.L. 1996: Predator-induced life history changes: Antipredator behavior costs or facultative life history shifts? Ecology 77: 1116-1124 .

BARNARD D.R. \& GEDEN C.J. 1993: Influence of larval density and temperature in poultry manure on development of the house fly. Environ. Entomol. 22: 971-977.

BAUERFEIND S.S. \& Fischer K. 2005: Effects of food stress and density in different life stages on reproduction in a butterfly. Oikos 111: 514-524.

BECKERMAN A.P., WIESKI K. \& BAIRD D.J. 2007: Behavioural versus physiological mediation of life history under predation risk. Oecologia 152: 335-343.

Berner D. \& Blanckenhorn W.U. 2007: An ontogenetic perspective on the relationship between age and size at maturity. Funct. Ecol. 21: 505-512.

Berrigan D. \& Koella J.C. 1994: The evolution of reaction norms - simple-models for age and size at maturity. J. Evol. Biol. 7: 549-566.

Brodmann P.A., Wilcox C.V. \& Harrison S. 1997: Mobile parasitoids may restrict the spatial spread of an insect outbreak. J. Anim. Ecol. 66: 65-72.

Cote I.M. \& Poulin R. 1995: Parasitism and group-size in social animals - a metaanalysis. Behav. Ecol. 6: 159-165.

Crowl T.A. \& Covich A.P. 1990: Predator-induced life-history shifts in a fresh-water snail. Science 247: 949-951.

DMITRIEw C. 2011: The evolution of growth trajectories: what limits growth rate? Biol. Rev. 86: 97-116.

EsPerk T. \& TAMmaru T. 2010: Size compensation in moth larvae: attention to larval instars. Physiol. Entomol. 35: 222-230.

Foster B.A. \& Stiven A.E. 1996: Experimental effects of density and food on growth and mortality of the southern Appalachian land gastropod, Mesodon normalis (Pilsbry). Am. Midl. Nat. 136: 300-314.

Friberg M., Aalberg Haugen I.M, Dahlerus J., Gotthard, K. \& WikLund C. 2011: Asymmetric life-history decisionmaking in butterfly larvae. Oecologia 165: 301-310.

GÅRDMARK A. \& DieCKMANN U. 2006: Disparate maturation adaptations to size-dependent mortality. Proc. R. Soc. (B, Biol. Sci.) 273: 2185-2192.

Gebhardt M.D. \& Stearns S.C. 2002: Reaction norms for developmental time and weight at eclosion in Drosophila mercatorum. J. Evol. Biol. 1: 335-354.

GotTHARD K. 2000: Increased risk of predation as a cost of high growth rate: an experimental test in the speckled wood butterfly, Pararge aegeria. J. Anim. Ecol. 69: 896-902.

Greer A.L., Briggs C.J. \& Collins J.P. 2008: Testing a key assumption of host-pathogen theory: density and disease transmission. Oikos 117: 1667-1673.

Haukioja E., Pakarinen E., Niemelä P. \& Iso-Iivari L. 1988: Crowding-triggered phenotypic responses alleviate conse- 
quences of crowding in Epirrita autumnata. Oecologia 75: $549-558$.

Hulden L. 2000: Suomen Suurperhosatlas. [Atlas of Finnish Macrolepidoptera.] Suomen Perhostutkijain Seura/Luonnontieteellinen Keskusmuseo, Helsinki, 328 pp.

IsHII M. 1994: Factors determining larval, pupal and adult polyphenisms in the tropical butterfly, Catopsilia Pomona (Lepidoptera, Pieridae). Trans. Lepidopterol. Soc. Japan 45: 105-112.

JohANSSON F. \& Rowe L. 1999: Life history and behavioural responses to time constraints in a damselfly. Ecology 80: $1242-1252$

Johansson F., Stoks R., Rowe L. \& De Block M. 2001: Life history plasticity in a damselfly: Effects of combined time and biotic constraints. Ecology 82: 1857-1869.

Kenward M.G. \& Roger J.H. 1997: Small sample inference for fixed effects from restricted maximum likelihood. Biometrics 53: 983-997.

KLingenber C.P. \& Spence J.R. 1997: On the role of body size for life-history evolution. Ecol. Entomol. 22: 55-68.

Leraut P. 2009: Moths of Europe. Vol. 2. Geometrid Moths. NAP Editions, Paris, $43 \mathrm{pp}$.

Lester R.L., Grach C., Pener M.P. \& Simpson S.J. 2005: Stimuli inducing gregarious colouration and behaviour in nymphs of Schistocerea gregaria. J. Insect Physiol. 51: 737-747.

Littell R.C., Milliken G.A., Stroup W.W. \& Wolfinger R.D. 1996: SAS System for Mixed Models. SAS Institute, Cary, NC, 633 pp.

Marty L., Dieckmann U., Rochet M.J. \& Ernande B. 2011: Impact of environmental covariation in growth and mortality on evolving maturation reaction norms. Am. Nat. 117: 98-118.

Porter J. 1997: The Colour Identification Guide to Caterpillars of the British Isles. Penguin, London, $69 \mathrm{pp}$.

Remmel T., Tammaru T. \& Mägr M. 2009: Seasonal mortality trends in tree-feeding insects: a field experiment. Ecol. Entomol. 34: 98-106.

RIESSEN H.P. 1999: Predator-induced life history shifts in Daphnia: a synthesis of studies using meta-analysis. Can. J. Fish. Aquat. Sci. 56: 2487-2494.

RofF D.A. 1992: The Evolution of Life Histories. Chapman \& Hall, London, pp. 24-56.

RotнмаN L.D. 1997: Immediate and delayed effects a viral pathogen and density on tent caterpillar performance. Ecology 78: $1481-1493$.

Rudolf V.H.W. \& Roedel M.O. 2007: Phenotypic plasticity and optimal timing of metamorphosis under uncertain time constraints. Evol. Ecol. 21: 121-142.
Remmel T., Davison J. \& Tammaru T. 2011: Quantifying predation on folivorous insect larvae: The perspective of lifehistory evolution. Biol. J. Linn. Soc. 114: 1-18.

RuohomäKi K., Klemola T., Kaitaniemi P. \& KäÄr M. 2003: Crowding-induced responses in a geometrid moth revisited: a field experiment. Oikos 103: 489-496.

SAS Institute INc. 1990: SAS/STAT User's Guide. Version6, $4^{\text {th }}$ $e d$. SAS Institute Inc., Cary, NC.

Sillanpä̈̈ S. 2008: How do food quality and larval crowding affect performance of the autumnal moth, Epirrita autumnata. Entomol. Exp. Appl. 129: 286-294.

Smits A. 2002: Performance of pine looper Bupalus piniarius larvae under population build-up conditions. Entomol. Exp. Appl. 104: 117-124.

STEARNS S.C. 1992: The Evolution of Life Histories. Oxford University Press, Oxford, pp. 123-149.

Stearns S.C. \& Koella J.C. 1986: The evolution of phenotypic plasticity in life-history traits - predictions of reaction norms for age and size at maturity. Evolution 40: 893-913.

StILING P.D. 1988: Density-dependent processes and key factors in insect populations. J. Anim. Ecol. 57: 581-593.

TAMMARU T. 1998: Determination of adult size in a folivorous moth: constraints at instar level? Ecol. Entomol. 23: 80-89.

TAMMARU T. \& ESPERK T. 2007: Growth allometry of immature insects: larvae do not grow exponentially. Funct. Ecol. 21: 1099-1105.

Tammaru T., RuohomäKi K. \& Montola M. 2000: Crowdinginduced plasticity in Epirrita autumnata (Lepidoptera: Geometridae): weak evidence of specific modifications in reaction norms. Oikos 90: 171-181.

Tammaru T., Nylin S., RuohomäKi K. \& Gotthard K. 2004: Compensatory responses in lepidopteran larvae: a test of growth rate maximisation. Oikos 107: 352-362.

Tammaru T., Tanhuanpää M., Ruhomäki K. \& Vanatoa A. 2001: Autumnal moth - why autumnal? Ecol. Entomol. 26: 646-654.

Tauber M.J., Tauber C.A. \& Masaki S. 1986: Seasonal Adaptations of Insects. Oxford, New York, $411 \mathrm{pp}$.

Teder T., Esperk T., Remmel T., Sang A. \& Tammaru T. 2010: Counterintuitive size patterns in bivoltine moths: late-season larvae grow larger despite lower food quality. Oecologia 162: $117-125$.

Wahlberg N., Snäll N., Viidalepp J., RuohomäKi K. \& TamMARU T. 2010: The evolution of female flightlessness among Ennominae of the Holarctic forest zone (Lepidoptera, Geometridae). Mol. Phylogen. Evol. 55: 929-938.

WALL R. \& BEGON M. 1987: Individual variation and the effects of population density in the grasshopper Chorthippus brunneus. Oikos 49: 15-27.

Received February 21, 2011; revised and accepted November 7, 2011 